\title{
Utilização do exame citológico no diagnóstico de afecções de cães e gatos
}

\author{
Use of Cytological examination in the diagnosis of dog and cat diseases \\ Uso del examen citológico em el diagnóstico de afecciones de perros y gatos
}

\section{Resumo}

Este trabalho verificou a utilização do diagnóstico citológico, como método de identificação de afecções em cães e gatos domiciliados no município de Barra-BA atendidos no Hospital Veterinário Universitário (HVU) da Universidade Federal do Oeste da Bahia (UFOB). O estudo foi realizado a partir da análise de amostras citológicas relativas aos casos clínicos atendidos nos anos de 2018 e 2019. Foram atendidos 711 animais, desses contabilizadas 105 (101 caninos e 4 felinos - 59 fêmeas e 46 machos) solicitações do exame citológico. A maioria dos animais $(28,57 \%)$ apresentavam de 6 a 10 anos, prevalecendo os animais Sem Raça Definida (62,38\%). Os processos inflamatórios foram diagnosticados em 43,80\% dos casos, identificados como de causa infecciosa em 86,90\% (30\% por Leishmania spp., 27,5\% infecções bacterianas, 27,5\% pela levedura Malassezia spp. e outros $15 \%$ por associação deste fungo a bactérias). Os processos inflamatórios de origem não infecciosa foram registrados em 13,10\% casos ( $84 \%$ infiltrados de células inflamatórias e $16 \%$ como dermatite por lambedura). Observou-se processos não inflamatórios em 19,05\% das amostras, sendo 95\% de origem neoplásica, (63,15\% TVT, 21,05\% Carcinoma de Células Escamosas, 10,05\% Adenocarcinoma e 5,30\% Tricoblastoma). Já entre os processos não inflamatórios e não neoplásicos (5\%) diagnosticou-se um cisto epidérmico (100\%). A aplicabilidade do diagnóstico citológico em cães e gatos denota importância uma vez que, auxiliou médicos veterinários na confirmação de suspeitas clínicas, permitindo a emissão de laudos diagnósticos, estabelecimento de tratamentos e dados epidemiológicos que possibilitam a implantação de medidas de controle das enfermidades.

Palavras-chave: Citologia; Imprint; Neoplasias; Processos infecciosos; Swab.

\section{Abstract}

This work verified the use of cytological diagnosis, as a method of identification of disorders in dogs and cats domiciled in the municipality of Barra-BA seen at the University Veterinary Hospital (HVU) of the Federal University of Western Bahia (UFOB). The study was conducted from the analysis of cytological samples related to 
clinical cases seen in the years 2018 and 2019. A total of 711 animals were seen, of these counted 105 (101 canines and 4 felines - 59 females and 46 males) requests for the cytological examination. Most of the animals $(28.57 \%)$ were 6 to 10 years old, with the prevalence of No Defined Breed animals $(62.38 \%)$. The inflammatory processes were diagnosed in $43.80 \%$ of the cases, identified as having infectious cause in $86.90 \%$ (30\% by Leishmania spp., $27.5 \%$ bacterial infections, $27.5 \%$ by the yeast Malassezia spp. and other $15 \%$ by association of this fungus with bacteria). Inflammatory processes of non-infectious origin were recorded in $13.10 \%$ cases $(84 \%$ infiltrated by inflammatory cells and $16 \%$ as lick dermatitis). Non-inflammatory processes were observed in $19.05 \%$ of the samples, $95 \%$ of which were of neoplastic origin, $(63.15 \%$ TVT, 21.05\% Squamous Cell Carcinoma, 10.05\% Adenocarcinoma and $5.30 \%$ Trichoblastoma). Among the non-inflammatory and non-neoplastic processes (5\%) an epidermal cyst was diagnosed $(100 \%)$. The applicability of cytological diagnosis in dogs and cats denotes importance since it helps veterinarians in confirming clinical suspicions, allowing the issuance of diagnostic reports, establishment of treatments and epidemiological data that enable the implementation of control measures of diseases.

Keywords: Cytology; Imprint; Neoplasms; Infectious processes; Swab.

\section{Resumen}

Este estudio verificó el uso del diagnóstico citológico, como método de identificación de trastornos en perros y gatos domiciliados en el municipio de Barra-BA atendidos en el Hospital Veterinario Universitario (HVU) de la Universidad Federal del Oeste de Bahía (UFOB). El estudio se realizó a partir del análisis de muestras citológicas relacionadas con casos clínicos atendidos en los años 2018 y 2019. Se atendieron 711 animales, de los cuales se contabilizaron 105 (101 caninos y 4 felinos - 59 hembras y 46 machos) solicitudes de examen citológico. La mayoría de los animales $(28,57 \%)$ tenían entre 6 y 10 años, prevaleciendo los animales Sin Raza Definida (62,38\%). Los procesos inflamatorios se diagnosticaron en el $43,80 \%$ de los casos, identificándose como causa infecciosa en el $86,90 \%$ (30\% por Leishmania spp., 27,5\% infecciones bacterianas, $27,5 \%$ por la levadura Malassezia spp. y otro $15 \%$ por asociación de este hongo con bacterias). Los procesos inflamatorios de origen no infeccioso se registraron en el $13,10 \%$ de los casos (el $84 \%$ infiltrados por células inflamatorias y el $16 \%$ como dermatitis por lamido). Se observaron procesos no inflamatorios en el 19,05\% de las muestras, de las cuales el $95 \%$ eran de origen neoplásico, (63,15\% TVT, 21,05\% Carcinoma de células escamosas, 10,05\% Adenocarcinoma y 5,30\% Tricoblastoma). Entre los procesos no inflamatorios y no neoplásicos (5\%) se diagnosticó un quiste epidérmico (100\%). La aplicabilidad del diagnóstico citológico en perros y gatos denota importancia una vez, ayudó a los médicos veterinarios en la confirmación de las sospechas clínicas, permitiendo la emisión de informes diagnósticos, establecimiento de tratamientos y datos epidemiológicos que hacen posible la implantación de medidas de control de las enfermidades.

Palabras clave: Citología; Huella; Neoplasias; Procesos infecciosos; Hissopo.

\section{Introdução}

O diagnóstico citológico é descrito como um método preciso, de baixo custo e exato na obtenção de resultados, auxiliando médicos veterinários na investigação e identificação da suspeita clínica (Corrêa et al., 2018). É uma técnica minimamente invasiva, apresenta segura execução, além de proporcionar ampla superfície de amostragem e rápido tempo entre o processo de diagnóstico e o resultado (Magalhães et al., 2014). Baseia-se na análise da célula de forma individual, fornecendo informações relacionadas a sua origem, permitindo, por exemplo, a identificação e diferenciação de inflamação, hiperplasia, infecções ou a presença de tumores sejam eles cancerígenos ou não, determinando o prognóstico do animal, a presença de metástases e evolução/involução do quadro clínico (Rosolem et al., 2013). A obtenção de resultados clinicamente relevantes depende, dentre outros fatores, da colheita de boas amostras contendo áreas representativas da lesão, sem artefatos ou contaminação, corados por métodos que evidenciem tanto critérios citoplasmáticos quanto critérios nucleares, levando em consideração a espécie animal, o histórico clínico e descrição macroscópica das lesões (Coleto et al., 2016).

O conteúdo a ser utilizado no estudo citológico pode ser obtido a partir de técnicas de biópsias, que proporcionam coleta de tecido ou grupo celular, como a Punção Aspirativa por Agulha Fina (PAAF), a qual possibilita avaliação de glândulas, nódulos, massas ou tumores firmes ou de difícil esfoliação a partir da pressão. Já a capilaridade é utilizada para tecidos de proliferação e muito vascularizado como linfonodos, obtendo células por meio da capilaridade alcançada com a utilização de seringa e agulha fina. A biópsia esfoliativa é descrita para coletar em locais externos, como em casos de lesões de pele, onde o material é obtido com uma lâmina de bisturi ou vidro. A biópsia por imprint direto pode ser utilizada para obtenção de células superficiais através da aposição da lâmina de microscopia no local lesionado, funcionando como um 
"adesivo". A biópsia por imprint indireto é utilizado swab, cotonete, escova citológica e pontas aplicadoras para coletar o material, também se fundamenta no contato e é optada quando outros métodos não são aplicáveis para determinada região, como por exemplo, na mucosa vaginal ou da orelha externa (Ana Mendes et al., 2021; Rosolem et al., 2013).

Diante das mais diversas enfermidades que acometem animais domésticos, verificar a utilização do diagnóstico citológico, como método de identificação de afecções em cães e gatos domiciliados no município de Barra-BA, denota importância, pois na região estudada não existem dados literários sobre estudos citológicos como exames de rotina em medicina veterinária. Esta pesquisa, ainda possibilita o conhecimento das principais enfermidades locais, ressaltando quadros infecciosos e neoplásicos, permitindo a determinação de dados epidemiológicos, que contribuirão para estudos futuros, estes podem servir como base para outras áreas geográficas que comportem o mesmo perfil socioeconômico e cultural da região estudada. Dessa forma, o trabalho teve como objetivo verificar a utilização do diagnóstico citológico, como método de identificação das afecções em cães e gatos domiciliados no município de Barra-BA, atendidos na Clínica Médica Veterinária de Pequenos Animais (CMPA), do Hospital Veterinário Universitário (HVU) da Universidade Federal do Oeste da Bahia UFOB, Campus Multidisciplinar de Barra.

\section{Metodologia}

\section{Local do estudo e amostragem}

O estudo foi realizado a partir da análise de amostras citológicas relativas aos casos clínicos atendidos durante os anos de 2018 e 2019. Realizando-se assim, uma verificação epidemiológica onde se determinou a frequência (absoluta e relativa) da utilização do exame citológico na prática veterinária, evidenciando o total de animais atendidos no HVU-UFOB - Campus Multidisciplinar de Barra, o ano correspondente ao atendimento, a espécie, raça, idade e sexo, além da determinação das afecções mais diagnosticadas com esse exame, divididas em categorias relacionadas à origem das lesões.

Avaliação clínica e colheita de amostras

Todos os pacientes utilizados na pesquisa passaram por consulta clínica, houve a caracterização das lesões macroscópicas quanto à morfologia (elevada, plana, deprimida, nodular, massa), consistência (firme, macia, friável, flutuante), coloração (azulado, avermelhado, amarelado, transparente), localização (regiões e proximidades) e distribuição (focal, multifocal, difusa) (Buckles et al., 2017).

Em seguida, a colheita de material biológico ocorreu de acordo com a forma mais indicada para cada caso: PAAF (Punção Aspirativa por Agulha Fina), capilaridade, biópsia esfoliativa, biópsia por imprint direto ou indireto (Raskin, 2012a). O conteúdo foi adicionado a lâminas de vidro e por meio da técnica squash ou rolamento redistribuído para formar uma fina e monocamada, facilitando a penetração dos corantes. A lâmina com o material biológico, foi encaminhada imediatamente ao Laboratório de Análises Clínicas da mesma instituição, foi corada pelo método panótico rápido e analisada com auxílio de microscópio óptico comum (aumento 40x e 100x, nesse último com a utilização do óleo de imersão) (Thrall et al., 2017).

\section{Classificações dos resultados}

Os casos avaliados receberam classificação de acordo com a origem das lesões em quatro grandes categorias: Categoria 1, composta por processos inflamatórios, sendo esses infecciosos ou parasitários e não infecciosos; Categoria 2, composta por processos não-inflamatórios neoplásicos ou não-neoplásicos; Categoria 3, diagnóstico inconclusivo; Categoria 4, resultados negativos, verificando-se o tecido celular sem alterações.

Análises de dados

Foi utilizada a estatística descritiva, determinando frequências absolutas e relativas (Estrela, 2018). Os resultados foram

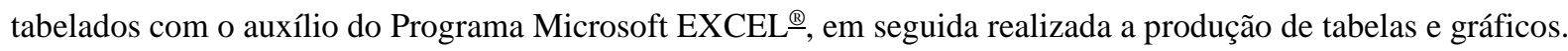




\section{Comissão de ética em uso de animais}

O trabalho foi aprovado pela Comissão de Ética em Uso de Animais (CEUA) da Universidade Federal do Oeste da Bahia (UFOB), recebendo o número de protocolo 00172019. Realizado com o financiamento do Programa Institucional de Apoio ao Discente-Ações Afirmativas (PRODISCENTE - Iniciação Científica - EDITAL N. 01/2019).

\section{Resultados}

No período compreendido entre 2018 e 2019, foram atendidos 711 animais (514 cães e 197 gatos) no HVU-UFOB e 105 desses necessitaram do exame citológico, sendo que em 2018, 35 (33\%) animais foram submetidos ao exame e no ano de 2019, 70 (67\%).

A espécie canina prevaleceu no número de atendimentos citológicos - 101 (96,2\%), registrando-se apenas 4 (3,8\%) felinos. Do total de animais, 59 (56,19\%) foram fêmeas e 46 (43,81\%) machos. Já sobre a idade, foi dividida em 4 grupos, 7 (6,66\%) animais foram agrupados em menores que 1 ano, 51 (48,57\%) estiveram entre 1 a 5 anos, $30(28,57 \%)$ alocaram-se entre 6 a 10 anos e 17 animais (16,20\%) foram registrados como maiores que 11 anos.

No que diz respeito ao estudo das raças, nos caninos prevaleceram os animais Sem Raça Definida (SRD) 63 (62,38\%), seguidos da raça Pinscher 8 (7,92\%), Poodle 7 (6,93\%), Boxer e Shih-tzu com 6 cada (5,94\%), Dobermann, Pastor Belga, Chihuahua, Pequinês, e Golden Retriever com 1 (0,99\%) cada e Labrador, Dachshund e Pitbull com 2 (1,98\%) cada. Enquanto nos felinos houve predominância de animais SRD (100,00\%).

Diante das 105 amostras analisadas foi estabelecido diagnóstico confirmatório citológico em 66 (62,85\%) casos, divididos entre inflamatórios 46 (43,80\%) e não inflamatórios 20 (19,05\%). As amostras negativas para a suspeita clínica, ou seja, onde não se observou alterações no tecido celular perfizeram 17 casos $(16,20 \%)$ e 22 (20,95\%) foram considerados inconclusivos. (Tabela 1) 
Tabela 1: Afecções de cães e gatos diagnosticados pelo exame citológico entre os anos de 2018 e 2019 na CMPA do HVUUFOB.

\begin{tabular}{|c|c|c|}
\hline \multirow{12}{*}{$\frac{\text { PROCESSOS INFLAMATÓRIOS }}{46(43,80 \%)}$} & \multirow{8}{*}{$\begin{array}{c}\text { Causa infecciosa } \\
40(86,90 \%)\end{array}$} & Leishmaniose \\
\hline & & $12(30 \%)$ \\
\hline & & Infecção bacteriana \\
\hline & & $11(27,5 \%)$ \\
\hline & & Malasseziose \\
\hline & & $11(27,5 \%)$ \\
\hline & & Associação fúngica e bacteriana \\
\hline & & $6(15 \%)$ \\
\hline & \multirow{4}{*}{$\begin{array}{c}\text { Causa não infecciosa } \\
6(13,10 \%)\end{array}$} & $\begin{array}{c}\text { Infiltrado de células } \\
\text { inflamatórias }\end{array}$ \\
\hline & & $5(84 \%)$ \\
\hline & & Dermatite por lambedura \\
\hline & & $1(16 \%)$ \\
\hline \multirow{5}{*}{$\begin{array}{l}\text { PROCESSOS NÃO } \\
\text { INFLAMATÓRIOS }\end{array}$} & \multirow{8}{*}{$\begin{array}{c}\text { Origem neoplásica } \\
19(95 \%)\end{array}$} & TVT \\
\hline & & $12(63,15 \%)$ \\
\hline & & $\mathrm{CCE}$ \\
\hline & & $4(21,05 \%)$ \\
\hline & & Adenocarcinoma \\
\hline \multirow[t]{5}{*}{$20(19,05 \%)$} & & $2(10,50 \%)$ \\
\hline & & Tricoblastoma \\
\hline & & $1(5,30 \%)$ \\
\hline & $\begin{array}{l}\text { Origem não } \\
\text { neoplásica }\end{array}$ & Cisto epidémico \\
\hline & $1(5 \%)$ & $1(100 \%)$ \\
\hline \multirow{2}{*}{\multicolumn{3}{|c|}{$\frac{\text { CASOS INCONCLUSIVOS }}{22(20,95 \%)}$}} \\
\hline & & \\
\hline \multicolumn{3}{|l|}{ NEGATIVOS } \\
\hline $17(16,20 \%)$ & & \\
\hline
\end{tabular}

Fonte: Arquivo pessoal.

Os processos inflamatórios foram identificados como de causa infecciosa ou parasitária em $40(86,90 \%)$ amostras, nas quais $12(30 \%)$ foram diagnosticadas como Leishmania spp., $11(27,5 \%)$ confirmados para infecção bacteriana, observando-se formas de cocos ou bacilos, $11(27,5 \%)$ com predominância fúngica da levedura Malassezia spp., e em outras 6 (15\%) análises ocorreu a associação deste fungo a bactérias. Já os processos inflamatórios registrados como de origem não infecciosa, foram 6 $(13,10 \%)$, sendo $5(84 \%)$ infiltrados de células inflamatórias e $1(16 \%)$ caso definido como dermatite por lambedura. (Figura 1). As infecções bacterianas foram encontradas em descargas vaginais e prepuciais e as leveduras ou a sua associação com bactérias foram encontradas em cerúmen do conduto auditivo. 
Figura 1: Diagnóstico citológico dos processos inflamatórios de cães e gatos atendidos na Clínica Médica de Pequenos Animais do Hospital Veterinário Universitário -Universidade Federal do Oeste da Bahia.


Fonte: Arquivo pessoal.

A- Leishmaniose. Macrófagos com a presença de microrganismos intracelulares, distinguidos por um núcleo e cinetoplasto, caracterizado pela forma amastigota de Leishmania spp. B, C e D - Infecção Bacteriana. Presença de cocos, diplococos, estreptococos e bacilos basofílicos livres e fagocitados por células de defesa (ponta de seta). E - Malasseziose. Formas de leveduras em brotamento abundante, em formato de "pegadas". F - Associação fúngica e bacteriana. Presença de leveduras em brotamento e bactérias em forma de cocos, diplococos e estreptococos basofílicos. G - Infiltrado de células inflamatórias. Grande quantidade de células inflamatórias na ausência de patógenos. H - Dermatite por lambedura. Folhas de epitélio (células intermediárias menores) predominam, adjacente à neutrófilos.

Observou-se processos não inflamatórios de origem neoplásica em 19 (95\%) diagnósticos e 1 (5\%) considerado não neoplásico. Entre os processos não inflamatórios neoplásicos, esses em grande número foram identificados em animais dos grupos de 6 a 10 anos e maiores de 11 anos, sendo o Tumor Venéreo Transmissível (TVT) diagnosticado em 12 (63,15\%) 
casos, seguido por Carcinoma de Células Escamosas 4 (21,05\%), Adenocarcinoma 2 (10,5\%) e Tricoblastoma 1 (5,30\%). Já entre os processos não inflamatórios e não neoplásicos constatou-se 1 (100\%) cisto epidérmico. (Figura 2).

Figura 2: Diagnóstico citológico dos processos não inflamatórios de cães e gatos atendidos na Clínica Médica de Pequenos Animais do Hospital Veterinário Universitário - Universidade Federal do Oeste da Bahia.
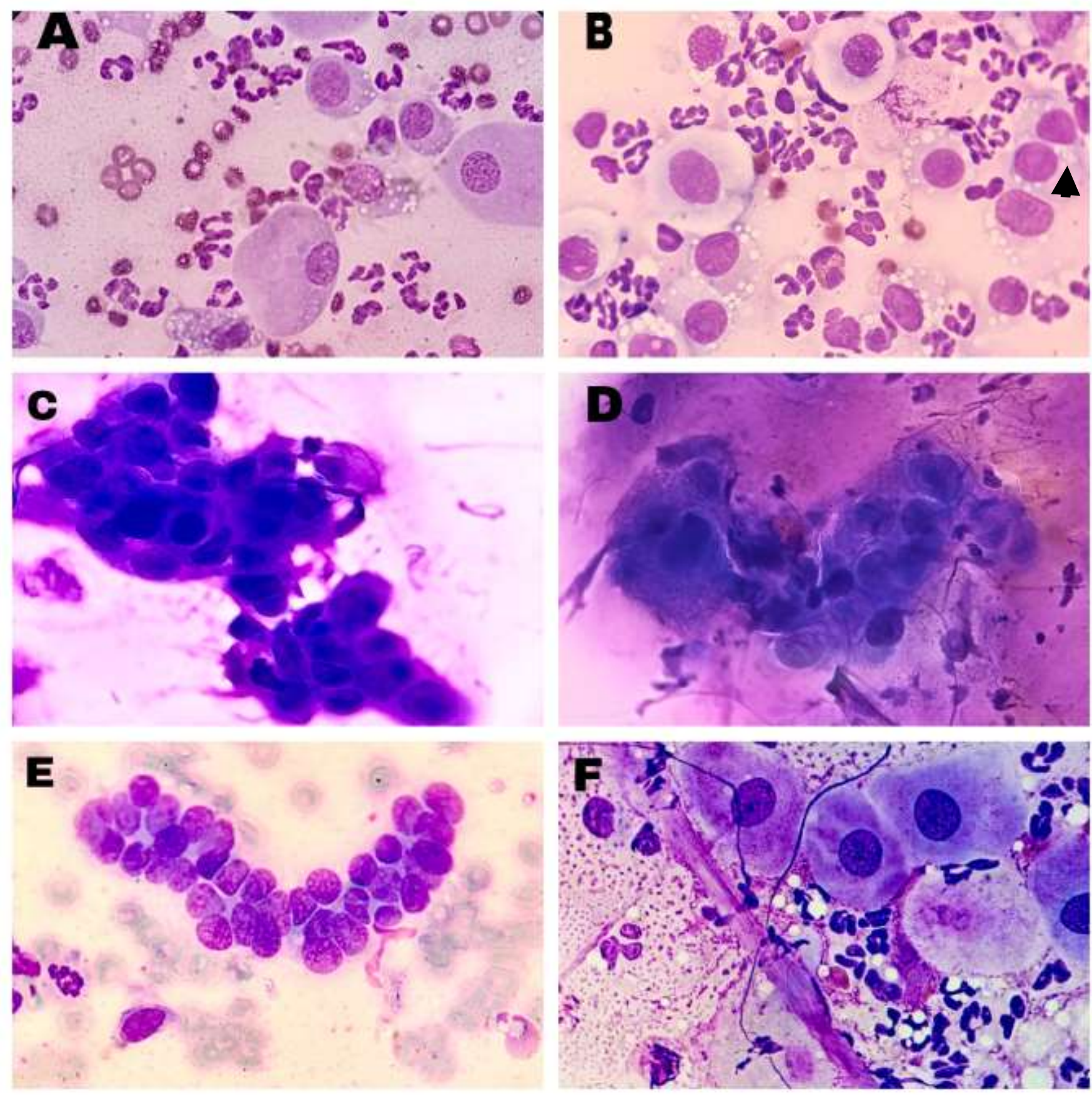

Fonte: Arquivo pessoal.

A e B - Tumor Venéreo Transmissível. Células redondas que possuem núcleo redondo, cromatina nuclear grosseira, nucléolo variavelmente proeminente e quantidades escassas a moderadas de citoplasma discretamente basofílico, contendo vacúolos. C - Carcinoma de células escamosas. Queratinização assincrônica, anisocariose, relação núcleo: citoplasma variável e cromatina grosseira. D Adenocarcinoma mamário. Estrutura acinar, com multinucleação e cromatina grosseira, assim como nucléolos proeminentes, anisocariose moderada e citoplasma acentuadamente basofílico. E - Tricoblastoma. Agrupamento compacto de células uniformes que apresentam alta proporção núcleo-citoplasma, citoplasma é escasso e basofílico. F - Cisto epidérmico. Presença de células inflamatórias, barras de queratina, células queratinizadas anucleadas e envoltas por debris granulares. 


\section{Discussão}

O número significativo de exames citológicos ao longo do período estudado demonstra a aplicabilidade da técnica e eficácia para a determinação diagnóstica na rotina clínica. A comprovação do alto grau de acurácia/especificidade da técnica, semelhante a este trabalho, também foi evidenciada por Vasconcelos et al. (2016), denotando assim a importância da citologia diagnóstica na rotina de clínicas e hospitais veterinários, auxiliando a emissão de laudos conclusivos. Ressalta-se que em alguns casos a associação a outros testes complementares se faz necessária (Peters et al., 2016; De Oliveira et al., 2020; S. Silva et al., 2020), a exemplo de exames microbiológicos e histopatológicos, aumentando a confiabilidade desta técnica e proporcionando maior implementação na eficácia terapêutica.

A prevalência de cães no estudo é compatível com a predominância dessa espécie na região estudada, corroborando com a Associação Brasileira da Indústria de Produtos para Animais de Estimação que cita uma população canina no Brasil em torno de 56 milhões animais. Houve maior índice de atendimento de animais pertencentes ao sexo feminino, semelhante ao relatado por Cardoso (2003) e Rosolem et al. (2013), porém não existe correlação de predisposição sexual de cães e gatos para o desenvolvimento de enfermidades diagnosticadas pela citologia.

A grande diversidade etária dos pacientes reflete mais uma vez o público de animais atendidos no hospital veterinário que demandou não apenas do diagnóstico tumoral, mas também diagnóstico de processos inflamatórios. Quanto ao diagnóstico neoplásico, esse foi mais encontrado em animais de meia-idade a geriátricos, o fator idade para ocorrência de neoplasias é amplamente estudado, uma vez que quanto maior a longevidade do indivíduo maiores as chances de mutações em genes que levam ao desenvolvimento de neoplasias, devido ao maior tempo de exposição a agentes carcinogênicos (Gomes et al., 2006; Rosolem et al., 2013; Tedardi et al., 2016).

No que diz respeito as raças, as que mais necessitaram do auxílio diagnóstico citológico foram: SRD, Pinscher, Poodle, Boxer e Shih-Tzu. Estas raças são mais observadas na região, gerando a hipótese de que elas estão mais envolvidas no diagnóstico pelo fato de serem mais comuns (Rosolem et al., 2013).

Entre os processos inflamatórios de causa infecciosa a leishmaniose destacou-se na área estudada. Pesquisas tem comprovado na região de Barra, Oeste da Bahia a presença de flebotomíneos da espécie Lutzomyia longipalpis, difusores do protozoário, e aqui ressalta-se a população canina como uma das preferenciais em seu repasto sanguíneo (Cordeiro et. al., 2019; Diamantino et al., 2021). Altos níveis de parasitemia podem ser correlacionados à intensa infecção pelos protozoários observada na citologia, o que provavelmente indica a fase aguda da infecção, período em que a multiplicação e desenvolvimento do agente é maior (Monteiro, 2017), por conseguinte, permitindo a visualização do protozoário com maior facilidade, como demonstrado neste trabalho. Antunes et al. (2018) cita a citologia aspirativa como uma técnica segura para detecção microscópica de formas amastigotas da Leishmania spp. e alternativa para a determinação da intensidade parasitária, ficando atrás apenas do qPCR quantitativo, destacando então o seu baixo custo, alta sensibilidade, que segundo Coleto et al. (2016) é de 77\%, e especificidade, segundo Rodríguez et al. (2009) é 93\%.

Destacaram-se entre as demais afecções inflamatórias as ocasionadas por bactérias e fungos leveduriformes, citados principalmente causando quadros de otites em cães, concordando com o trabalho de Teixeira et al. (2019) que apontam esta afecção como uma das desordens mais frequentes na espécie. Fato esse que poderia estar associado a fatores que podem alterar a homeostase da microbiota, como excesso de umidade, traumas, dermatite atópica, presença de ectoparasitas, conformação do conduto auditivo, produção excessiva de cerúmen ou tratamentos inadequados. Acredita-se que a predominância de cães da raça SRD neste trabalho, aliada ao baixo poder socioeconômico cultural dos tutores e a condição a qual os animais estão submetidos pode ter favorecido a implantação de fatores de risco para a afecção. Além dos quadros de otites, infecções genitais causadas por bactérias foram evidenciadas, o que segundo Sant'Anna et al. (2012) ocorre principalmente pela presença de descargas vaginais e prepuciais, correlacionadas a condições que propiciem a mudança da microbiota local. 
Destaca-se que a avaliação citológica de quadros infecciosos foi importante para garantir rapidez na emissão do laudo presuntivo, concordando com Teixeira et al. (2019), fornecendo assim um ponto de partida para o clínico iniciar um tratamento adequado. Ressalta-se que sua associação a exames microbiológicos confirmou a identificação do agente, possibilitando a confecção de testes de susceptibilidade antimicrobiana (Carvalho, 2017; De Oliveira et al., 2020), potencializando assim efetividade terapêutica.

Poucos casos neste trabalho foram diagnosticados como infiltrado inflamatório, se tratando mais de um achado laboratorial. Destaca-se, contudo que identificar os tipos de infiltrados e detectar a fase em que se encontra a reação possibilita diferenciar e descartar a presença de neoplasias (Ackermann, 2018; Rosolem et al., 2013).

Um dos animais deste estudo foi diagnosticado com dermatite por lambedura, uma das dermatopatias com maior dificuldade de tratamento, pois na maioria das vezes é causada por distúrbios comportamentais, podendo estar relacionada ou não com condições orgânicas. Apesar de ser uma enfermidade de baixa ocorrência, a citologia por imprint direto da lesão na lâmina, permitiu a observação ao microscópio de uma resposta inflamatória crônica, demonstrando a presença de células mononucleares, plasmócitos e epitélio escamoso intermediário, relacionados à lambedura ou mastigação, semelhante ao descrito em literatura (Raskin, 2012b; Lustoza et al., 2015), comprovando sua aplicabilidade para o diagnóstico efetivo da afecção supracitada.

Em relação a classificação de quadros não inflamatórios de causa neoplásica, o diagnóstico de TVT, tumor com origem das células redondas, prevaleceu. Por ser uma patologia oncológica que possui característica de implantação celular com proliferação tecidual em regiões genitais de cães, fatores sociais predispõem os cães à aquisição dessa afecção, como por exemplo, livre acesso à rua sem a presença do tutor, aglomerações, descontrole populacional de cães errantes e contato com animais enfermos (Peixoto et al., 2016; Ferreira et al., 2017). Nesse estudo a alta ocorrência de TVT pode ter prevalecido devido à grande incidência de cães errantes observados na cidade de Barra-BA, como citado por Diamantino et al. (2021) e K. Silva et al. (2020), possibilitando o contato com os fatores de risco citados acima. O emprego da técnica citológica atuou de forma significativa permitindo a identificação e tratamento dos animais, ampliando assim a viabilidade do emprego de estratégias de controle da enfermidade na cidade estudada.

O Carcinoma de Células Escamosas foi o tumor de células epiteliais mais diagnosticado, acometendo preferencialmente gatos a cães, corroborando com Raskin (2012b), que demonstra essa dermatopatia neoplásica correspondendo a $15 \%$ dos tumores de pele em gatos e apenas $2 \%$ em cães. As neoplasias relacionadas à pele e seus anexos são de importante relevância em países de clima tropical, como o Brasil, devido à exposição de forma crônica à radiação ultravioleta (Scopel, 2007). Gatos domésticos SRD, de pelos claros são mais predispostos, corroborando com este estudo (Melo et al., 2018).

O adenocarcinoma mamário foi classificado em terceiro lugar de ocorrência, similar ao apresentado por Salvado (2010) e divergindo de De Nardi et al. (2008) que classifica os tumores da glândula mamária em segundo lugar no ranking dos processos neoplásicos mais frequentes. Ressalta-se a importância do estudo citológico em casos que envolvem afecções mamárias, uma vez que, diagnósticos diferenciais importantes são citados, e o emprego da terapêutica adequada para cada um depende da confirmação diagnóstica, a exemplo de mastites, lipomas, mastocitomas, adenomas, tumor mamário misto maligno, fibroadenocarcinomas, entres outros (Furian et al., 2007; Soares et al., 2018).

$\mathrm{O}$ tricoblastoma, tumor de células basais que tem origem germinativa no pelo, foi a neoplasia menos diagnosticada. De fato, a ocorrência de tricoblastoma é pequena, representando aproximadamente 2 a 2,6\% das neoplasias cutâneas em cães (Dos Santos, 2016). Salienta-se que esse reduzido percentual de casos, pode estar relacionado com a baixa ocorrência ou subdiagnóstico clínico, citológico e histopatológico da lesão. Portanto chama-se a atenção de médicos veterinários para utilização de diagnósticos confirmatórios, a exemplo do citológico, para comprovação da veracidade desse percentual, uma vez 
que, é importante destacar que o tratamento dessa enfermidade é baseado na excisão cirúrgica total da neoplasia, possuindo um prognóstico favorável de reabilitação (Souza et al., 2020).

$\mathrm{O}$ cisto epidérmico, diagnosticado com maior facilidade pela histopatologia também e distinguindo citologicamente de outros cistos, uma vez observado barras de queratina, escamas ou outros queratinócitos. Sua baixa frequência neste trabalho, foi semelhante ao explicitado por Fragoso et al. (2016) e Raskin, (2012b) que o citam como de identificação rara. Entretanto, salienta-se que o conhecimento e prática na leitura das lâminas citológicas permitiu a visualização dessa afecção sem complicações, proporcionando fechamento de laudo diagnóstico.

\section{Conclusão}

A utilização do exame citológico na região de Barra, Oeste da Bahia se mostrou de grande importância, proporcionando resultados efetivos de diagnóstico que possibilitaram o auxílio no tratamento e consequentemente a criação de dados epidemiológicos que podem possibilitar a implantação de medidas de controle das enfermidades. Com isso, indica-se o uso rotineiro desta técnica associada ao exame clínico na prática veterinária, por ser de fácil execução, baixo custo e de grande valor na determinação do diagnóstico de leishmaniose, infecções bacterianas e fúngicas, processos inflamatórios, cisto epidérmico e quadros neoplásicos, além de possíveis outras enfermidades que não foram identificadas nesse estudo. Devido a importância dessas doenças identificadas com o uso da citologia, recomenda-se que mais estudos sobre as suas características clínicas, laboratoriais e epidemiológicas sejam realizadas na região estudada.

\section{Agradecimentos}

Agradeço a equipe do Laboratório de Análises Clínicas do HVU-UFOB pela colaboração, aos autores pela ajuda na realização do manuscrito e ao Programa Institucional de Apoio ao Discente-Ações Afirmativas (PRODISCENTE - Iniciação Científica) que possibilitou a realização desta pesquisa.

\section{Referências}

Antunes, T. R., Godoy, K. C. S., Oliveira, G. G., Silveira, A.W., Ramos, C. A. N. R., \& Souza, A. I. (2018). Técnicas de citologia aspirativa, biópsia e citobloco de medula óssea para identificação e determinação de intensidade parasitária na leishmaniose visceral canina. Arquivo Brasileiro de Medicina Veterinária e Zootecnia, 70(5): 1362-1368.

Ackermann, M. R. (2018). Inflamação e Cicatrização. In: Zachary, J. F. Bases da Patologia em Veterinária. (6ª ed.): Elsevier, 3 : $73-132$.

Buckles, E., Duhamel, G., Kelly, K., Miller, A., \& Peters-Kennedy, J. (2017). Necropsy guide for dogs, cats, and small mammals. 1st ed. Wiley blackwell: 330 .

Cardoso, M. J. L., Machado, L. H. A., Rocha, N. S., Moutinho, F. Q., \& Ciampolini, P. (2003). Linfoma canino: Revisão de cinquenta e quatro casos. Journal of Biosciences, 19: 131- 142 .

Carvalho, L. C. A. (2017). Etiologia e resistência de bactérias isoladas de otite externa de cães. 2017. Dissertação (Mestrado em Ciências Biológicas) Universidade Federal do Rio Grande do Norte, Natal, RN, Brasil.

Coleto, A. F., Moreira, T. A., Gundim, L. F., Silva, S. A., Castro, M. R., Bandarra, M. B., \& Medeiros-Ronchi., A. A. (2016). Perfil de exames citológicos, sensibilidade e especificidade da punção por agulha fina em amostras cutâneas e subcutâneas em cães. Revista Brasileira Medicina Veterinária: 5.

Corrêa, J. M. X., Oliveira, N. G. S. G., Silva, F. L., Michel, A. F. R. M., Lavoer, M. S. L., Silva, E. B., \& Carlos, R. S. A. (2018). O Diagnóstico preciso muda o prognóstico do paciente felino com carcinoma de células escamosas? Revista Científica de Medicina Veterinária - Pequenos Animais e Animais de Estimação, 15(46): 54-60.

Cordeiro, A. K. P., Fagundes A. I. S., Silva, C. M. A., Silva, M. B., Conceição, M. S., \& Magalhães Junior, J. T. (2019). Ocorrência de flebotomíneos na zona urbana do município de Barra, Bahia. In: $54^{\circ}$ Congresso da Sociedade Brasileira de Medicina Tropical (Olinda, Brazil).

De Comunicação, A. E. (2021). Mercado PET Brasil: 2021. Associação Brasileira da Indústria de Produtos para Animais de Estimação. http://abinpet.org.br/mercado.

De Nardi, A. B. (2009). Neoplasias mamárias. In: Daleck, C. R., De Nardi, A. B., \& gatos. Revista De Ciência Veterinária E Saúde Pública, $3(1)$ : $37-43$. 
De Oliveira, A. P., dos Santos, J. P., de Souza, V. F. M., de Oliveira Carneiro, I., \& da Silva Vieira, L. C. A. (2020). Associação Do Exame Microbiológico E Citológico No Diagnóstico De Otite Externa Em Cães E Gatos. Associação Do Exame Microbiológico E Citológico No Diagnóstico De Otite Externa Em Cães E Gatos, 1-388.

Diamantino, L. U. S., de Oliveira, A. P., dos Santos Andrade, K., da Conceição Santos, M. W., Pereira, Z. S., de Melo Mendonça, F. L., \& da Silva Vieira, L. C. A. (2021). Transmissible Venereal Tumor Associated with Cutaneous Metastasis and Leishmaniasis in a Bitch. Acta Scientiae Veterinariae, 49.

Dos Santos, I. F. C., Cardoso, J. M. M., Soares, J. F., Carla, A., Assis, G., Reis, M. G., \& Tannus, F. C. I. (2016). Tricoblastoma Em Cão Jovem (Canis Lupus Familiaris)-Primeiro Relato De Caso Na República De Moçambique, África. Acta Veterinaria Brasilica, 357-362.

Estrela, C. (2018). Metodologia científica: ciência, ensino, pesquisa. Artes Médicas.

Ferreira, M. A. Q. B., Teixeira M. N., Carvalho, C. C. D., Paiva, B. H. A., Silva, V. C. L., Fukahori, F. L. P., Rêgo, M. S. A., Dias, M. B. M. C., \& Lima, E. R. (2017). Aspectos clínicos, hematológicos, bioquímicos e citopatológicos do Tumor Venéreo Transmissível em cães tratados com sulfato de vincristina. Medicina Veterinária (Universidade Federal Rural do Pernambuco). 11(1): 8-17.

Furian, M., Sandei, C. F. C. S., Rocha, E. J. N., \& Lot, R. F. E. (2007). Estudo retrospectivo dos tumores mamários em caninos e felinos atendidos no hospital veterinário da FAMED entre 2003 a 2007. Revista Científica Eletrônica de Medicina Veterinária, 8: 1-5.

Fragoso, T. L., de Carvalho, L. A., Bernieri, E. M., de Oliveira, G. P., Anderlini, S., \& Dos Santos, K. C. (2016). Cisto Epidérmico: Relato De Caso. Anais 2016 VI Simpósio de Medicina Veterinária do Centro Universitário Cesmac, 24.

Gomes, C., Ferreira, M. P., da Silva Ferreira, K. C. R., Cavalcanti, R. L., Spagnol, C., de Oliveira, L. O., \& de Oliveira, R. T. (2006). Estudo epidemiológico de cães com imagens radiográficas compatíveis com neoplasias ósseas. Acta Scientiae Veterinariae, 34(2): 159-162.

Lustoza, A. B., da Silva, L. K. B., Gogola, R., \& de Fátima França, J. (2015). Dermatite Piotraumática Em Cão-Relato De Caso. Revista Eletrônica Biociências, Biotecnologia E Saúde, 3(12): 11-12.

Magalhães, A. M., Ramadinha, R. R., Barros, C. S., \& Peixoto, P. V. (2014). Estudo comparativo entre citopatologia e histopatologia no diagnóstico de neoplasias caninas. Pesquisa Veterinária Brasileira, 21: 23-32.

Melo, G. C., Valadão, L. C., Costa, P. H., Jeunon, F. A., Leal, R. M., \& Grandinetti, H. D. A. M. (2018). Carcinoma De Células Escamosas Em Língua: Relato De Caso Clínico. Revista Intercâmbio, 12, 116.

Mendes, A. P. M., Vandresen, G., \& Almeida, J. E. P. (2021). Diagnóstico citológico em cães: um estudo comparativo entre técnicas de coleta. Monografia (Graduação em Medicina Veterinária) - Universidade do Sul de Santa Catarina, Brasil.

Monteiro, S. G. Parasitologia na medicina veterinária: Roca, (2ª ed,) 2017.

Peters, L. M., Glanemann, B., Garden, O. A., \& Szladovits, B. (2016). Achados citológicos de 140 amostras de bile de cães e gatos e dados patológicos clínicos associados. Journal of veterinary internal medicine, 30 (1): 123-131.

Peixoto, P. V., Teixeira, R. S., Mascarenhas, M. B., do Nascimento França, T., de Azevedo, S. C. S., Reinacher, M., \& Ramadinha, R. R. (2016). Formas atípicas e aspectos clínico-epidemiológicos do tumor venéreo transmissível canino no Brasil. Brazilian Journal of Veterinary Medicine, 38(2): 101-107.

Raskin, R. (2012a). Obtenção e Manuseio de Amostras Citológicas. In: Raskin, R., Meyer, D. J. E. Citologia clínica de cães e gatos: atlas colorido e guia de interpretação. ( $2^{\mathrm{a}}$ ed.): Elsevier, Cap. 1: 23-51.

Raskin, R. (2012b). Pele e tecido subcutâneo. In: Raskin, R., \& Meyer, D. J. Citologia clínica de cães e gatos: atlas colorido e guia de interpretação. (2ª ed.): Elsevier, Cap. 1: 78-171.

Rodríguez, B. J., Ortiz, L. C., Garzón, A., Gómez, L. F., \& Vasquez, Y. (2009). Valo-ración de la citologia para el diagnóstico de tumores en caninos. Revista Colombiana de Ciencias Pecuarias, 22:42-53.

Rosolem, M. C., Moroz, L. R., Rodigheri, S. M., Corrêa Neto, U. J., Porto, C. D., \& Hanel, J. S. (2013). Estudo retrospectivo de exames citológicos realizados em um Hospital Veterinário Escola em um período de cinco anos. Arquivo Brasileiro de Medicina Veterinária e Zootecnia, 65: 735-741.

Salvado, I. S. S. (2010). Estudo Retrospectivo Das Neoplasias Em Canídeos E Felídeos Domésticos, Analisadas Pelo Laboratório De Anatomia Patológica Da Faculdade De Medicina Veterinária Da Universidade Técnica De Lisboa, No Período Compreendido Entre 2000 E 2009. Dissertação (Mestrado) - Curso de Medicina Veterinária, Universidade Técnica de Lisboa, Lisboa, Portugal.

Sant'Anna, M. C., Fabretti, A. K., \& Martins, M. I. M. (2012). Clinical approach to canine vaginitis. Semina: Ciências Agrárias, 33(4): 1543-1553.

Silva, C. Z. (2014). Identificação e susceptibilidade de bactérias isoladas de otite externa em cães aos antimicrobianos. Monografia (Graduação em Medicina Veterinária) - Faculdade de Veterinária, Universidade Federal do Rio Grande do Sul, Porto Alegre, Brasil.

Silva, S. A., Martins, D. S., da Silva, L. F., \& Bezerril, J. E. (2020). Exame citopatológico na medicina veterinária. Brazilian Journal of Development, 6(6): 39519-39523.

Silva, K. P. M., Rodrigues, V. T. S., Junior, G. J. D. S. R., Carneiro, I. O., Júnior, D. C. G., \& Vieira, L. C. A. S. (2020). Infecção Natural por Trypanosoma cruzi em Cão do Estado da Bahia-Nordeste do Brasil. Acta Scientiae Veterinariae, 48.

Scopel, D., Spader, M. B., Guim, T. N., Danieli, V. M., \& Fernandes, C. G. (2007). Estudo retrospectivo da casuística de carcinoma de células escamosas em felinos, bovinos, caninos, equinos e ovinos entre os anos de 2002 e 2006 no lrd/ufpel. iN congresso de iniciação cientifica e encontro de pós-graduação, 16.

Soares, J. V. G., Daneze, E. R., Salomão, R. L., \& de Paula, C. J. S. (2018). Adenocarcinoma complexo grau II de glândula mamária em uma cadela da raça bichon frisé. Nucleus Animalium, 10(1): 35-44. 
Research, Society and Development, v. 10, n. 12, e224101220350, 2021

(CC BY 4.0) | ISSN 2525-3409 | DOI: http://dx.doi.org/10.33448/rsd-v10i12.20350

Souza, V. F. M., Pereira, Z. S., Carneiro, I. O., Júnior, D. C. G., Frade, M. T. S., \& Vieira, L. C. A. S. (2020). Trichoblastoma in a Dog: A Clinical, Diagnostic and Therapeutic Analysis. Acta Scientiae Veterinariae, 48.

Tedardi, M.V., Kimura, K. C., Medonça, P. P., \& Dagli, M. L. Z. (2016). Epidemiologia e Etiologia do Câncer. In: Daleck, C. R., De Nardi, A. B. Oncologia em cães e gatos. $\left(2^{\mathrm{a}}\right.$. ed.): Editora Roca, 1: 22-64.

Thrall, M. A., Weiser, G., Allison, R. W., \& Campbell, T. W. (2017). Princípios gerais de exames e diagnósticos e laboratoriais. In: Weiser, G. Hematologia e bioquímica clínica veterinária. ( $2^{\mathrm{a}}$ ed.) Editora Roca, 1: 2-27.

Teixeira, M. G. F., Lemos, T. D., de Mello Bobany, D., Silva, M. E. M., Bastos, B. F., \& de Mello, M. L. V. (2019). Diagnóstico citológico de otite externa em cães. Brazilian Journal of Animal and Environmental Research, 2(5): 1693-1701.

Vasconcelos, T. C. B., Machado, L. C., Abrantes, T. R., Menezes, R. C., Madeira, M. F., Ferreira, L. C., \& Figueiredo, F. B. (2016). Avaliação da confiabilidade entre dois avaliadores nos exames citopatológico e imunocitoquímico do aspirado de medula óssea no diagnóstico da leishmaniose visceral canina. Arquivo Brasileiro de Medicina Veterinária e Zootecnia, 68 (3): 821-824. 